\title{
Downward Vascular Translocation of a Green Fluorescent Protein-Tagged Strain of Dickeya sp. (Biovar 3) from Stem and Leaf Inoculation Sites on Potato
}

\author{
Robert Czajkowski, Waldo J. de Boer, Johannes A. van Veen, and Jan M. van der Wolf
}

First, second, and fourth authors: Plant Research International, P.O. Box 16, 6700 AA, Wageningen, The Netherlands; first and third authors: Department of Terrestrial Microbial Ecology, Netherlands Institute of Ecology (NIOO-KNAW), Heteren, The Netherlands), Boterhoeksestraat 48, 6666 GA Heteren, The Netherlands; and third author: Institute of Biology, University of Leiden, Sylviusweg 72, 2333 BE Leiden, The Netherlands.

Accepted for publication 2 June 2010.

\begin{abstract}
Czajkowski, R., de Boer, W. J., van Veen, J. A., and van der Wolf, J. M., 2010. Downward vascular translocation of a green fluorescent proteintagged strain of Dickeya sp. (biovar 3) from stem and leaf inoculation sites on potato. Phytopathology 100:1128-1137.

Translocation of a green fluorescent protein (GFP)-tagged Dickeya sp. from stems or from leaves to underground parts of potato plants was studied in greenhouse experiments. Thirty days after stem inoculation, $90 \%$ of plants expressed symptoms at the stem base and $95 \%$ of plants showed browning of internal stem tissue. The GFP-tagged Dickeya sp.

parenchyma cells whereas, in stems and stolons, the GFP-tagged Dickeya sp. was found in the xylem vessels and protoxylem cells. In progeny tubers, this strain was detected in the stolon end. Thirty days after leaf inoculation, the GFP-tagged Dickeya sp. was detected in extracts of $75 \%$ of the leaves, $88 \%$ of the petioles, $63 \%$ of the axils, and inside $25 \%$ of the stems taken $15 \mathrm{~cm}$ above the ground level. UV microscopy confirmed the presence of the GFP-tagged Dickeya sp. inside petioles and in the main leaf veins. No blackleg or aerial stem rot and no translocation of the GFPtagged Dickeya sp. to underground plant parts was observed. The implications for contamination of progeny tubers are discussed.
\end{abstract} was detected by dilution plating in extracts of the stem interiors (100\%), stem bases $(90 \%)$, roots $(80 \%)$, stolons $(55 \%)$, and progeny tubers $(24 \%)$. In roots, the GFP-tagged Dickeya sp. was found inside and between
Additional keywords: confocal laser-scanning microscopy, Erwinia chrysanthemi, rep-PCR.
Dickeya spp. (syn. Erwinia chrysanthemi or Pectobacterium chrysanthemi) (37), together with Pectobacterium spp., are the causal organisms of blackleg, stem wet rot, and tuber soft rot diseases of potato. In Europe, Dickeya spp. in particular are causing increasing economic losses in seed potato production, mainly due to downgrading and rejection of seed lots $(20,35)$.

In 2005 , the former E. chrysanthemi species was reclassified into the genus Dickeya, which constitutes six different genomic species (genomo-species) inside nine biovars (37). According to this classification, potato strains in Europe isolated before 2000 almost all belonged to Dickeya dianthicola (previously E. chrysanthemi bv. dianthicola) (biovar 1, 7, and 9) (18,40). Since then, isolates belonging to a new genetic clade have been found frequently. This clade belongs to biovar 3 and possibly constitutes a new species (40). Strains belonging to this clade have been isolated from potato grown in Finland, Poland, the Netherlands, and Israel $(11,20,40,43)$; the United Kingdom (J. Elphinstone, personal communication); France (Y. le Hingrat, personal communication); and Belgium (J. Van Varenbergh, personal communication). Increased losses in seed potato production due to Dickeya spp. infection may be related to the occurrence of this new clade.

Potato blackleg is predominantly a seedborne disease, and the use of pathogen-free seed lots is the best measure to control blackleg and stem rot diseases. Blackleg symptoms are nearly

Corresponding author: J. M. van der Wolf; E-mail address: Jan.vanderWolf@wur.nl

*The $\boldsymbol{e}$-Xtra logo stands for "electronic extra" and indicates that Figures 1, 2, 4, 5, and 6 appear in color online.

doi:10.1094/PHYTO-03-10-0093

(C) 2010 The American Phytopathological Society always associated with the presence of rotten contaminated seed potato tubers, indicating its seedborne nature (30). An increase in tuber contamination and disease incidence within a seed lot occurs by spread of bacteria leaking from rotten tubers via soil water to daughter tubers in the field and, when soft, rotting tubers are present, due to smearing during harvest and grading (33).

Pathogen-free seed lots may become infected with blacklegand stem-rot-causing bacteria within a few generations of growing in the field. In The Netherlands, minitubers became infected within only two field generations: 17 of 50 seed lots were found contaminated with Dickeya spp. when tested by enrichment polymerase chain reaction (PCR) (45). Possibly the use of contaminated machines during harvest and grading is responsible for introducing the bacteria; however, other sources of contamination cannot be excluded.

Initially clean seed may also become contaminated during cultivation. Infection of potato plants may originate from contaminated machines used for spraying crop protection agents, contaminated insects, irrigation water, rain water, aerosols, human activity during field inspections, or animals entering potato fields $(8,29)$. In general, contamination via these sources more readily results in infection of haulms than underground plant parts. Aerial stem rot, which is frequently found in the field under wet conditions, may be the result of these introductions (33).

Progeny tubers may become colonized from infected haulm indirectly via soil or directly via translocation of bacteria inside plants. Bacteria washed off by rain from rotting stems and leaves into the soil may contaminate the progeny tubers. Despite the fact that Dickeya spp. cannot survive for a long time in soil, high numbers of bacteria washed from haulms and constantly reintroduced to the soil could result in tuber lenticel contamination (39). 
Bacteria in soil can also colonize roots and move via the vascular tissue of the roots into the stolons and, finally, in the progeny tubers (10)

It is unknown whether Dickeya spp. can be translocated from the haulm to underground plant parts (i.e., roots, stolons, and progeny tubers). Translocation of bacteria internally from aerial to underground plant parts has been described for only a few plantassociated bacteria. For example, Pseudomonas fluorescence injected into stems of mature maize plants could move $\approx 15 \mathrm{~cm}$ in stems above and below the inoculation point (14), Erwinia amylovora was isolated from roots after stab inoculation of apple seedlings (4), and Xanthomonas campestris pv. vitians was recovered from stem sections $2 \mathrm{~cm}$ below the inoculation site in stems of lettuce (2).

This study examines the ability of a strain belonging to the new biovar 3 genetic clade of Dickeya spp. to infect roots, stolons, and progeny tubers from inoculated potato haulm. In greenhouse experiments, the movement of the bacteria to underground parts was studied after stab inoculation of stems and inoculation by abrasion of leaves. We used a green fluorescent protein (GFP)tagged strain for monitoring the systemic movement of bacteria inside plants using epifluorescence stereomicroscopy (ESM), confocal laser-scanning microscopy (CLSM), and dilution-plating techniques.

\section{MATERIALS AND METHODS}

Bacterial strains and media used for cultivation. In all experiments, a GFP-tagged Dickeya sp., strain IPO2254, was used. This strain is a derivative of the wild-type biovar 3 Dickeya sp. IPO2222 (43) and contains the pPROBE-AT- $g f p$ plasmid (24) that confers stable production of GFP (10). Prior to use, Dickeya sp. IPO2254 was grown at $28^{\circ} \mathrm{C}$ for 24 to $48 \mathrm{~h}$ on tryptone soya agar (TSA) (Oxoid) or in nutrient broth (Difco Laboratories). For testing cavity formation, dilutions of isolates collected from infected plant material were plated on crystal violet pectate (CVP) (17). For pour plating, bacteria were grown in PT medium at $28^{\circ} \mathrm{C}$ for $24 \mathrm{~h}$ (34). Growth media were supplemented with ampicillin at $150 \mu \mathrm{g} \mathrm{ml}^{-1}$ and cycloheximide at $200 \mu \mathrm{g} \mathrm{ml}^{-1}$.

Growth of potato plants and inoculation with GFP-tagged Dickeya sp. Minitubers of cv. Kondor (Agrico, The Netherlands) were planted in potting soil in 5-liter plastic pots in a greenhouse and grown at a 16 -and-8-h photoperiod at 26 to $28^{\circ} \mathrm{C}$ and $\approx 70 \%$ relative humidity. Replicated experiments were conducted in June and November 2008. Inoculation of potato stems was performed 3 to 4 weeks after planting, when plants were $\approx 27$ to $30 \mathrm{~cm}$ high and stolons were already formed. In all, 20 plants (10 per experiment) were inoculated with the GFP-tagged Dickeya sp. strain, and 10 plants ( 5 plants per experiment) were used for the water-inoculated control. Stems were inoculated $10 \mathrm{~cm}$ above the ground level with either $100 \mu$ of the GFP-tagged Dickeya sp. in water at $10^{8} \mathrm{CFU} \mathrm{ml}{ }^{-1}$ or $100 \mu \mathrm{l}$ of sterile demineralized water (control). A 200- $\mu$ l yellow pipette tip was stabbed halfway into the stem at an angle of $45^{\circ}$ and subsequently wrapped with parafilm to prevent drying and leakage of bacteria along the stem surface to the soil. Three stems per potato plant were inoculated. To minimize the risk of soil contamination with the GFP-tagged Dickeya sp. strain released from diseased (rotten) stems, the soil surface was covered with plastic film. Plants were watered from the bottom of the pots.

Inoculation of potato leaves was done at the same time and in the same greenhouse as that used for stem inoculation but with a different set of plants (cv. Kondor). For each plant, seven randomly chosen leaves were inoculated by abrasion with $1 \mathrm{ml}$ of water suspension containing Dickeya sp. strain IPO2254 at $10^{8}$ $\mathrm{CFU} \mathrm{\textrm {ml } ^ { - 1 }}, 2.5 \%$ carborundum powder (Chemos $\mathrm{GmbH}$ ), and $0.1 \%$ Tween 20 (Oxoid). Control plants were inoculated with sterile water containing $2.5 \%$ carborundum powder and $0.1 \%$ Tween 20 . Both the axial and abaxial leaf surfaces were gently rubbed with the suspensions for $25 \mathrm{~s}$. In total, 16 plants (8 plants per experiment) were used for inoculation with the GFP-tagged Dickeya sp strain and a further 8 plants (4 plants per experiment) as a water-inoculated control. Direct soil contamination with the bacteria from inoculated leaves was prevented as with the steminoculated plants. Plants were also watered from the bottom of the pots.

Symptom development. Plants were visually inspected weekly for symptom development. Stem-inoculated plants were assessed for wilting, black rot on the stem base, aerial stem rot, haulm desiccation, and plant death. Leaf-inoculated plants were assessed for wilting and chlorosis of leaves, wilting of primary stems, wilting of secondary stems, aerial stem rot, typical blackleg, haulm desiccation, and plant death.

Sampling of stem and leaf-inoculated plants for PT pour plating. Per plant, 2-cm-long stem fragments at the inoculation point were collected from three stems and processed as a composite sample. Similarly, 2-cm-long stem fragments at the stem base were collected from the same three stems and processed as a composite sample. Per plant, the whole root system, three stolons, and six progeny tubers were tested separately. The sampled material was washed with tap water to remove soil particles, then surfacially sterilized with $70 \%$ ethanol for $1 \mathrm{~min}$, washed three times with water for $1 \mathrm{~min}$, held in $1 \%$ sodium hypochloride (commercial bleach) for $4 \mathrm{~min}$, and finally washed three times with water for $4 \mathrm{~min}$ each. Samples were weighed and a volume equivalent to twice the sample weight of 1/4 Ringer's buffer (Merck) was added. Each sample was crushed in a Universal Extraction bag (Bioreba) using a hammer. Then, $100 \mu \mathrm{l}$ of undiluted and $10 \times$ and $100 \times$ diluted samples were added to wells of a 24-well plate (Greiner BioOne) with $300 \mu$ of liquefied PT medium cooled down to 45 to $50^{\circ} \mathrm{C}$ supplemented with cycloheximide at $200 \mu \mathrm{g} \mathrm{ml}^{-1}$ and ampicillin at $150 \mu \mathrm{g} \mathrm{ml}^{-1}$. After the medium had solidified, plates were sealed with parafilm to prevent drying and incubated for 1 day at $28^{\circ} \mathrm{C}$. Plates were examined for the presence of GFP-tagged Dickeya sp. IPO2254 colonies under 495-nm blue light using an epifluorescence microscope (Leica Wild M32 FL4) equipped with a mercury high-pressure photo-optic lamp (Leica $\mathrm{Hg}$ 50W/AC) and GFP plus filter at a low magnification of $10 \times$ and $20 \times$.

Leaf-inoculated plants were sampled 30 days post inoculation (dpi). Seven inoculated leaves, seven leaf petioles, seven axils, seven $2-\mathrm{cm}$ stems segments taken $15 \mathrm{~cm}$ above ground level, seven $2-\mathrm{cm}$ stem base segments, whole root system, three stolons, and six progeny tubers were collected per plant and pooled per sample source. Plant parts were sterilized and processed for pour plating similarly as described for stem-inoculated plants.

Microscopic observations. Sample preparation. From every stem-inoculated plant, four roots at least $5 \mathrm{~cm}$ long, two $1-\mathrm{cm}$ stem base segments, two $2-\mathrm{cm}$ stem segments taken at the inoculation point, three stolons, and six progeny tubers were randomly selected.

From every leaf-inoculated plant, two leaves, four leaf petioles, four leaf axils, two stem base segments of $1 \mathrm{~cm}$, and two stem samples of $2 \mathrm{~cm}$ were randomly selected. Stem segments, stolons, and stolon ends of progeny tubers were transverse sectioned into $0.1-\mathrm{cm}$-thick pieces. All plant parts were washed and sterilized before microscopic observations as described for pour plating.

ESM. All plant samples were embedded in PT medium in petri dishes. The PT medium was liquefied by heating, cooled down to 45 to $50^{\circ} \mathrm{C}$, and supplemented with cycloheximide at $200 \mu \mathrm{g} \mathrm{ml}^{-1}$ and ampicillin at $150 \mu \mathrm{g} \mathrm{m} \mathrm{m}^{-1}$ before embedding. After the medium had solidified, plates were sealed with parafilm to prevent drying and incubated for 1 day at $28^{\circ} \mathrm{C}$. Samples were examined for the presence of a GFP-tagged Dickeya sp. under 495-nm blue light using an epifluorescence stereomicroscope 
(Leica Wild M32 FL4) equipped with a mercury high-pressure photo-optic lamp (Leica Hg 50W/AC) and GFP plus filter.

CLSM. Samples for the confocal laser-scanning microscope (Leica DM5500Q) were prepared in the same way as for the epifluorescence microscope. Samples were counterstained just before microscopic observations. For this, plant parts were washed from the agar and incubated for 0.5 to $1 \mathrm{~min}$ in a solution of propidium iodide (PI) (Invitrogen) at $20 \mu \mathrm{g} \mathrm{ml}^{-1}$. Samples were washed briefly with demineralized water and inspected under the microscope. For excitation of GFP and PI, a 485-nm blue laser was used. For GFP, a 505-nm emission filter was used; and, for PI, a 620-nm emission filter was used. Photographs were taken with a Leica Digital System (Leica) combined with a CSLM microscope using $10 \times$ and $63 \times$ water-immersion objectives.

Isolation of the GFP-tagged bacteria from infected plant material. GFP-tagged bacteria were isolated from plant parts
A

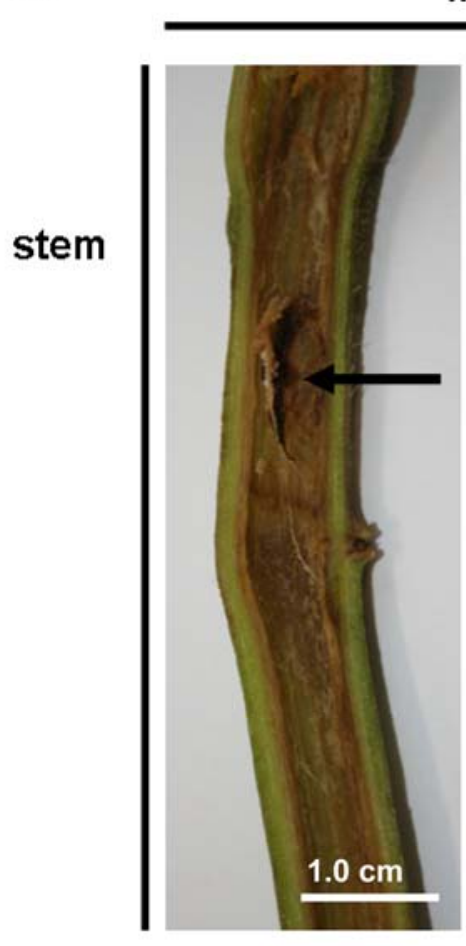

IPO2254

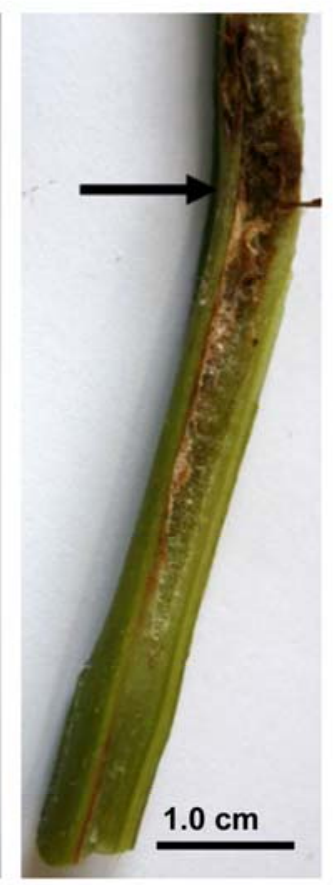

control

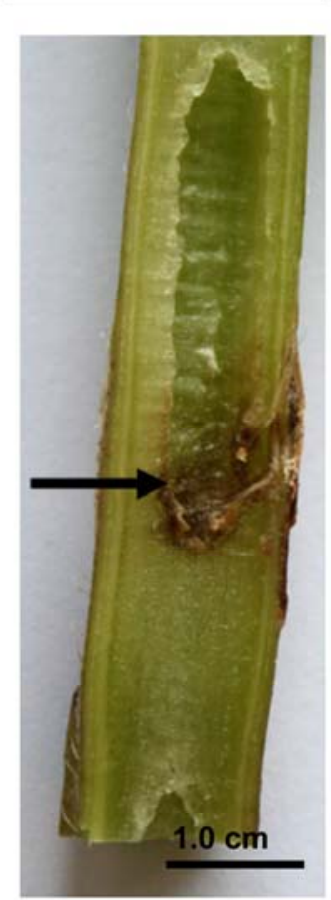

B

IPO2254
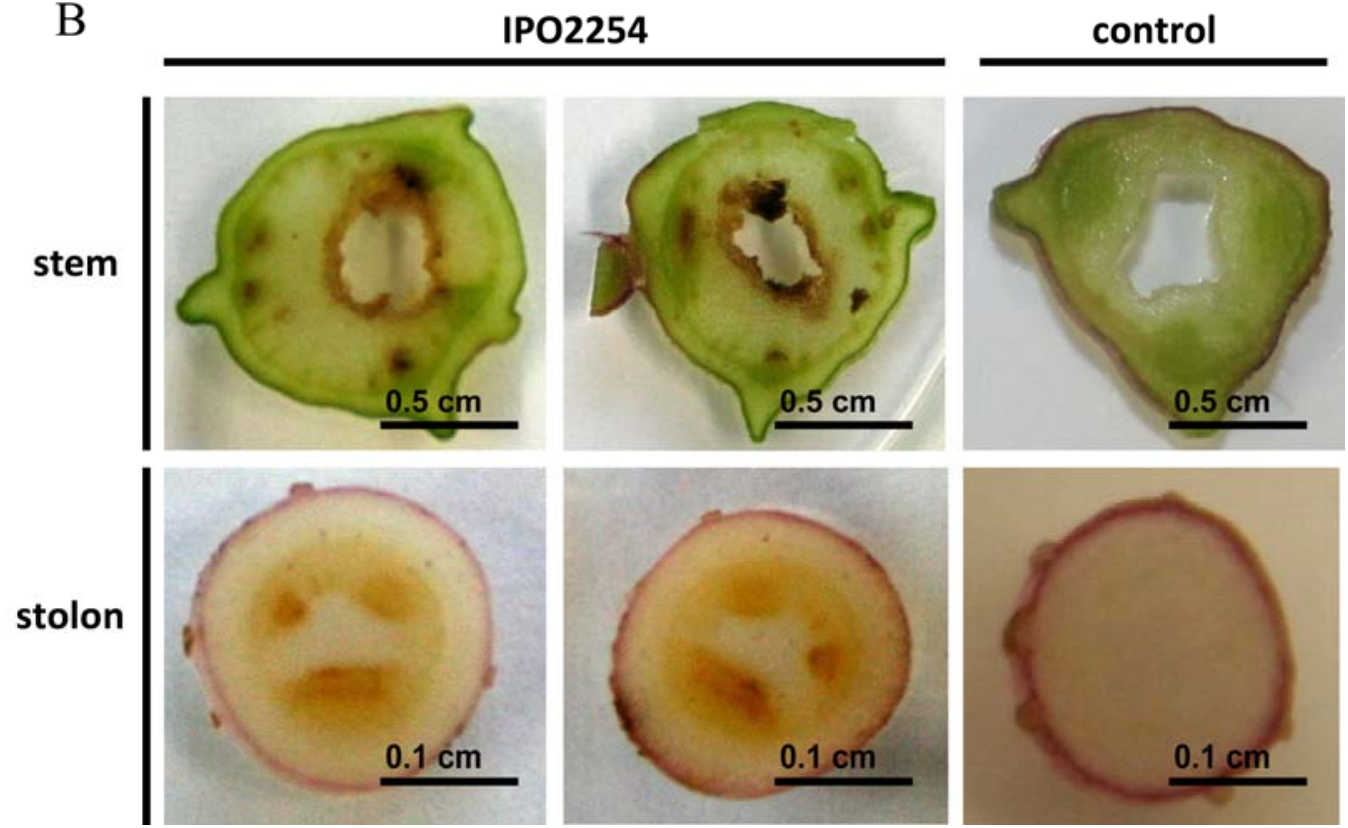

Fig. 1. Symptoms inside stems and stolons 30 days after stem inoculation. A, Sections of stems taken around the inoculation point (inoculation point marked with an arrow). Browning and blackening of the vascular- and pith tissue of stems observed above and below the inoculation point. B, Trans-sections of stems and stolons. Inoculated plants showing necroses (discoloration) of pith tissue. In both stems and stolons of inoculated plants, a necrosis of vascular tissue was found, resulting in light- and dark-brown lesions. Trans-sections of stems were taken $5 \mathrm{~cm}$ below the inoculation point. Control plants (water inoculated) were free of disease symptoms. Water-inoculated control plants showed only browning of pith tissue at the inoculation side. 
harboring GFP-tagged bacteria $30 \mathrm{dpi}$. For this, two stem samples at the inoculation point, two stem samples $10 \mathrm{~cm}$ below the inoculation point, two randomly chosen roots, two stolons, and two progeny tubers were collected from the stem-inoculated plants; two leaves, two axils, two petioles, and two stem base cuts were collected from leaf-inoculated plants. Collected parts were cut into small pieces and incubated in $0.5 \mathrm{ml}$ of Ringer's buffer for $20 \mathrm{~min}$ with shaking ( $\approx 200 \mathrm{rpm})$, and $100 \mu \mathrm{l}$ of each suspension was plated onto TSA containing ampicillin at $150 \mu \mathrm{g} \mathrm{ml}^{-1}$ or on CVP plates for testing cavity formation. GFP-positive and cavity-forming colonies were collected from the plates.

Identification of GFP-tagged bacteria by a Dickeya spp.specific PCR. For characterization of reisolated bacteria, a colony PCR procedure was used. Cells from GFP fluorescent or cavityforming colonies were collected from TSA (Oxoid) using a sterile toothpick, and resuspended in $50 \mu \mathrm{l}$ of $5 \mathrm{mM} \mathrm{NaOH}$. Suspensions were boiled for $5 \mathrm{~min}$ at $95^{\circ} \mathrm{C}$ and put on ice for 1 to $2 \mathrm{~min}$. Then, $1 \mu \mathrm{l}$ of the cell lysate was used as a template in PCR specific for Dickeya spp. with ADE1/ADE2 primers (ADE1: 5' GATCAGA AAGCCCGCAGCCAGAT $3^{\prime}$ and ADE2: 5' CTGTGGCCGAT CAGGATGGTTTTGTCGTGC 3') (25). Amplified DNA was detected by electrophoresis in a $1.5 \%$ agarose gel in $0.5 \times$ Tristborate-EDTA (TBE) buffer stained with ethidium bromide at $5 \mathrm{mg} \mathrm{m}{ }^{-1}$. The expected fragment length amplified by the ADE1/ADE2 primers for Dickeya spp. was $420 \mathrm{bp}$.

Identification of reisolated Dickeya sp. by repetitive element PCR fingerprinting. Repetitive element PCR fingerprinting (repPCR) was done on randomly chosen reisolates of a GFP-tagged Dickeya sp. as described before (46) using REP1R/REP2I primers (REP1R: 5' IIIICGICGICATCIGGC 3' and REP2I: 5' ICGIC TTATCIGGCCTAC 3'). The Qiagen Genomic DNA purification Kit (Qiagen) for gram-negative bacteria was used according to the manufacturer's instructions for purification of genomic bacterial DNA. The DNA concentration was adjusted with demineralized,

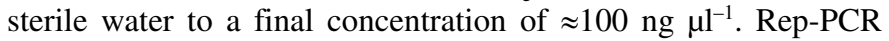
was performed in a total volume of $28 \mu \mathrm{l}$ using $6 \mathrm{U}$ of Taq polymerase (Roche) per reaction. Amplified DNA was analyzed by electrophoresis in a $1.5 \%$ agarose gel in $0.5 \times \mathrm{TBE}$ buffer and stained with ethidium bromide at $5 \mathrm{mg} \mathrm{ml}^{-1}$. The gel was run for 6 to $7 \mathrm{~h}$ at 90 to $95 \mathrm{~V}$ and at room temperature. A 1-kb ladder (BioRad) was used as a size marker.

Statistical analysis. Bacterial count data were analyzed using a generalized linear model (23) implemented within the statistical software package GenStat (27). Before applying the model, we estimated expected counts for samples that were recorded as uncountable due to high densities of cavity-forming bacteria (10). Briefly, the value $10^{6} \mathrm{CFU} \mathrm{\textrm {g } ^ { - 1 }}$ was taken as a likely cut-off level for the censored observations and bacterial density estimation was

TABLE 1. Plant samples analyzed by dilution plating for the presence of green fluorescent protein-tagged Dickeya sp. IPO2254 30 days after stem or leaf inoculation

\begin{tabular}{|c|c|c|c|}
\hline Plant part & No. tested & No. positive & Positive (\%) \\
\hline \multicolumn{4}{|l|}{ Stem inoculation } \\
\hline Inoculation point $\mathrm{a}^{\mathrm{a}}$ & 20 & 20 & 100 \\
\hline Stem base ${ }^{a}$ & 20 & 18 & 90 \\
\hline Roots ${ }^{b}$ & 20 & 16 & 80 \\
\hline Stolons ${ }^{c}$ & 60 & 33 & 55 \\
\hline Progeny tubers ${ }^{\mathrm{d}}$ & 120 & 32 & 24 \\
\hline \multicolumn{4}{|l|}{ Leaf inoculation } \\
\hline Leaves $^{\mathrm{e}}$ & 16 & 12 & 75 \\
\hline Petioles ${ }^{\mathrm{e}}$ & 16 & 14 & 88 \\
\hline Axils ${ }^{\mathrm{e}}$ & 16 & 10 & 63 \\
\hline Stems ${ }^{\mathrm{e}}$ & 16 & 4 & 25 \\
\hline Stem bases ${ }^{\mathrm{e}}$ & 16 & 0 & 0 \\
\hline Roots $^{b}$ & 16 & 0 & 0 \\
\hline Stolons ${ }^{c}$ & 48 & 0 & 0 \\
\hline Progeny tubers ${ }^{\mathrm{d}}$ & 96 & 0 & 0 \\
\hline
\end{tabular}

a Composite sample of three stem parts analyzed per plant.

b Total root system analyzed per plant.

c Three stolons individually analyzed per plant.

d Six progeny tubers individually analyzed per plant.

e Composite sample of seven plant parts analyzed per plant.
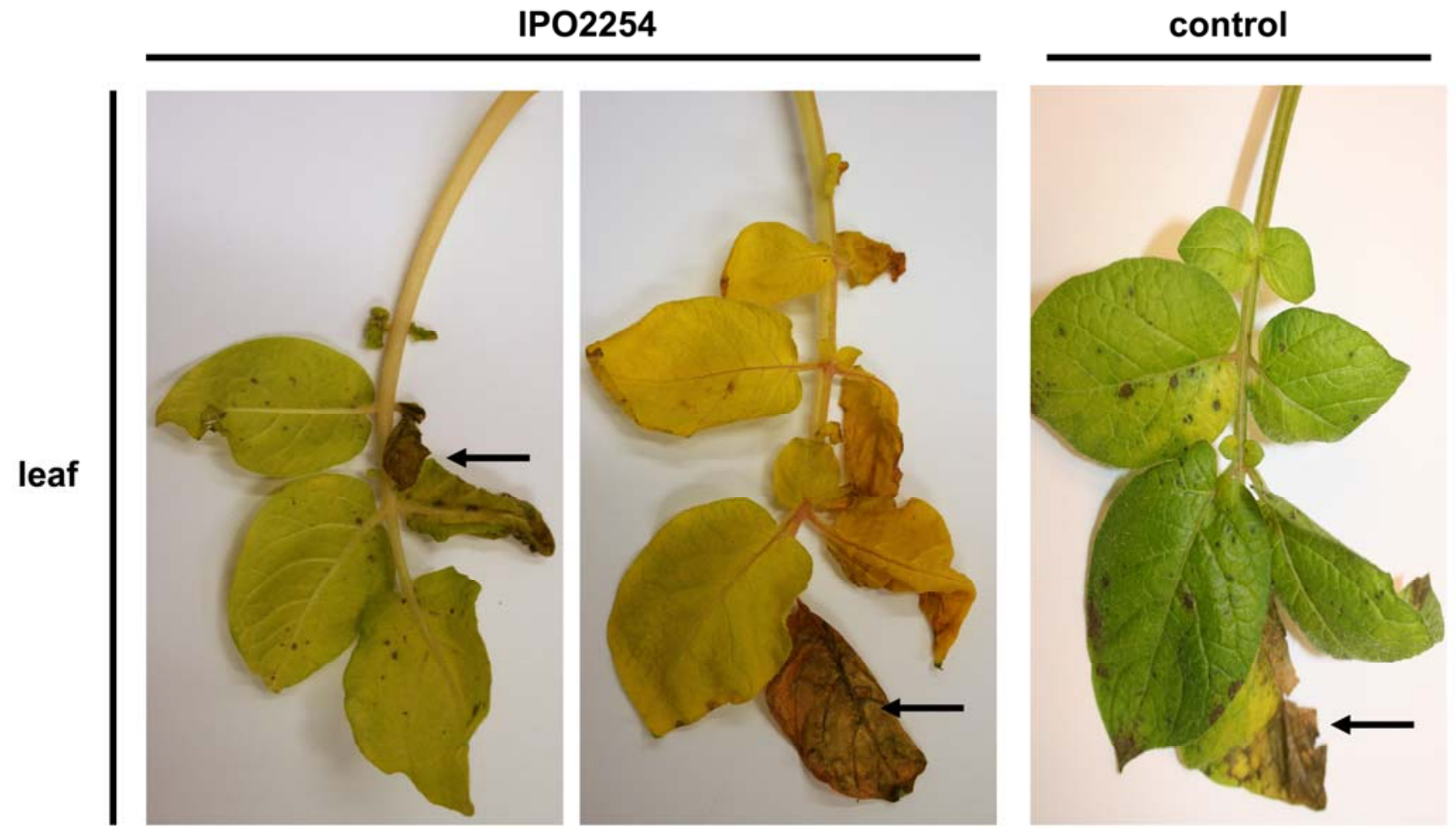

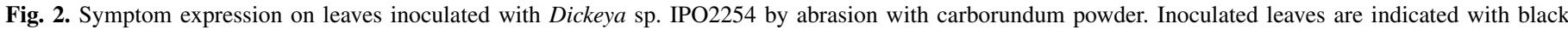

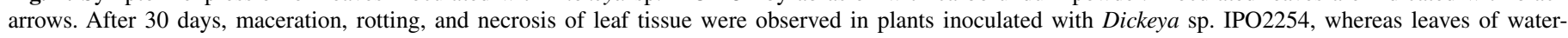
inoculated control plants showed only chlorosis and slight necrosis due to mechanical damage. 
based on normality assumptions (38). Count data were modeled using a standard Poisson regression method (7). In real count data, the underlying assumption of equality of mean and variance was rarely met. Most count data had variance greater than the mean or were Poisson overdispersed. The negative binomial distribution was the natural choice to model that overdispersed count data (16). Type of tissue effects were considered to be significant at $P \leq 0.05$, and pairwise differences were obtained using the $t$ test.

\section{RESULTS}

Symptom development. Fifteen days after stem inoculation, the first symptoms started to develop in inoculated plants. At $30 \mathrm{dpi}$, all stem-inoculated plants showed wilting and chlorosis of leaves. In $90 \%$ of plants, aerial stem rot, a typical blackening of the stem base, or both were observed. Trans-sections of stems of symptomatic plants showed degradation of vascular tissue and pith above and below the inoculation point, resulting in a hollowing of stems and browning of the internal stem tissue of 95\% of tested plants (Fig. 1).

In leaf-inoculated plants, the first symptoms appeared at $7 \mathrm{dpi}$; all inoculated leaves showed chlorosis and wilting. In the fol- lowing 2 weeks, these symptoms were also found frequently in adjacent leaves (Fig. 2). We did not observe symptoms on or in stems during the period of 30 days (data not shown).

Dilution plating of stem-inoculated plants. At $30 \mathrm{dpi}$, plant material was disinfected, extracted, and pour plated in PT to determine the percentage of infected plant tissues and to quantify populations of Dickeya sp. IPO2254. GFP-tagged cells were found at the point of inoculation of all plants. GFP-tagged cells were found in $90 \%$ of the stem bases, inside $80 \%$ of the roots, in $55 \%$ of the stolons, and in $24 \%$ of progeny tubers (Table 1). We did not detect GFP-tagged Dickeya spp. in any water-inoculated control plants.

At the inoculation point, the highest estimated densities of $10^{6}$ to $10^{7} \mathrm{CFU} \mathrm{g} \mathrm{g}^{-1}$ for the GFP-tagged Dickeya sp. were found (Fig. $3 \mathrm{~A})$. Densities at the stem base were still relatively high $\left(10^{4} \mathrm{CFU}\right.$

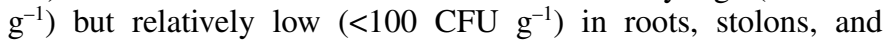
progeny tubers. Bacterial densities in stolons and progeny tubers varied largely per sample.

In $10 \%$ of stem-inoculated plants, no systemic colonization of GFP-tagged Dickeya sp. IPO2254 was found. In those plants, disease symptoms (rotting and browning of the tissues) and presence of bacteria were restricted to the inoculation site.

A

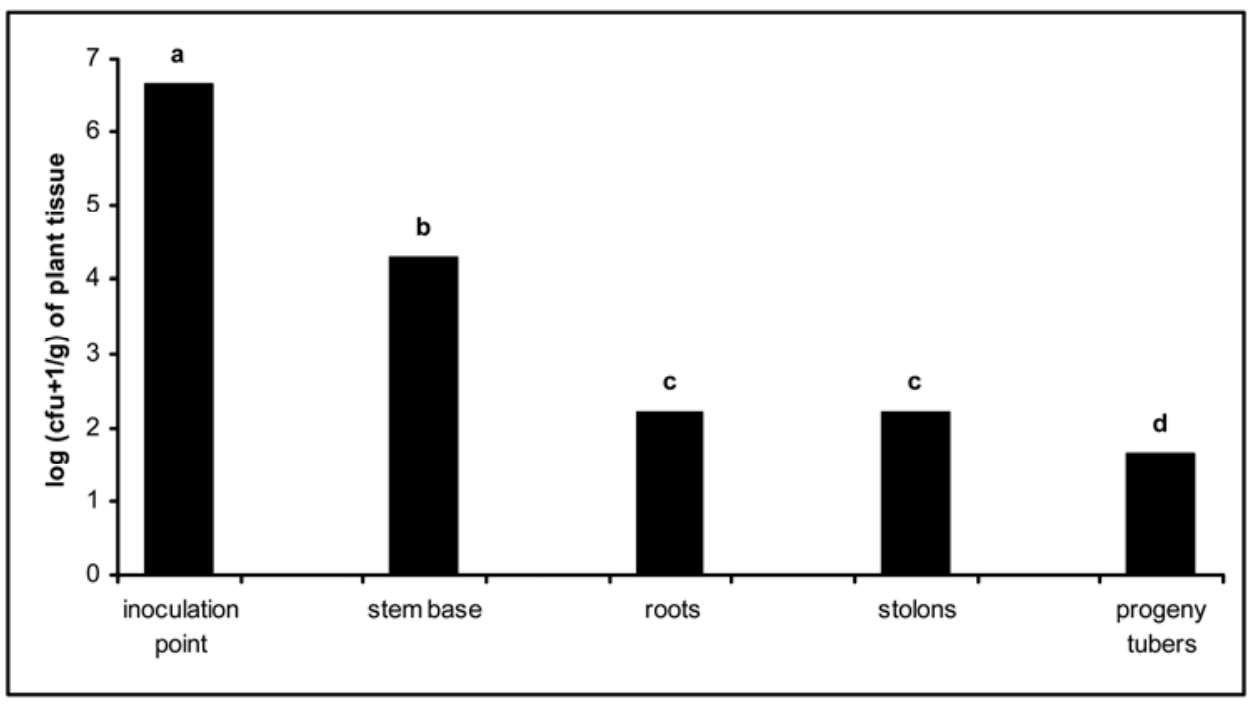

B

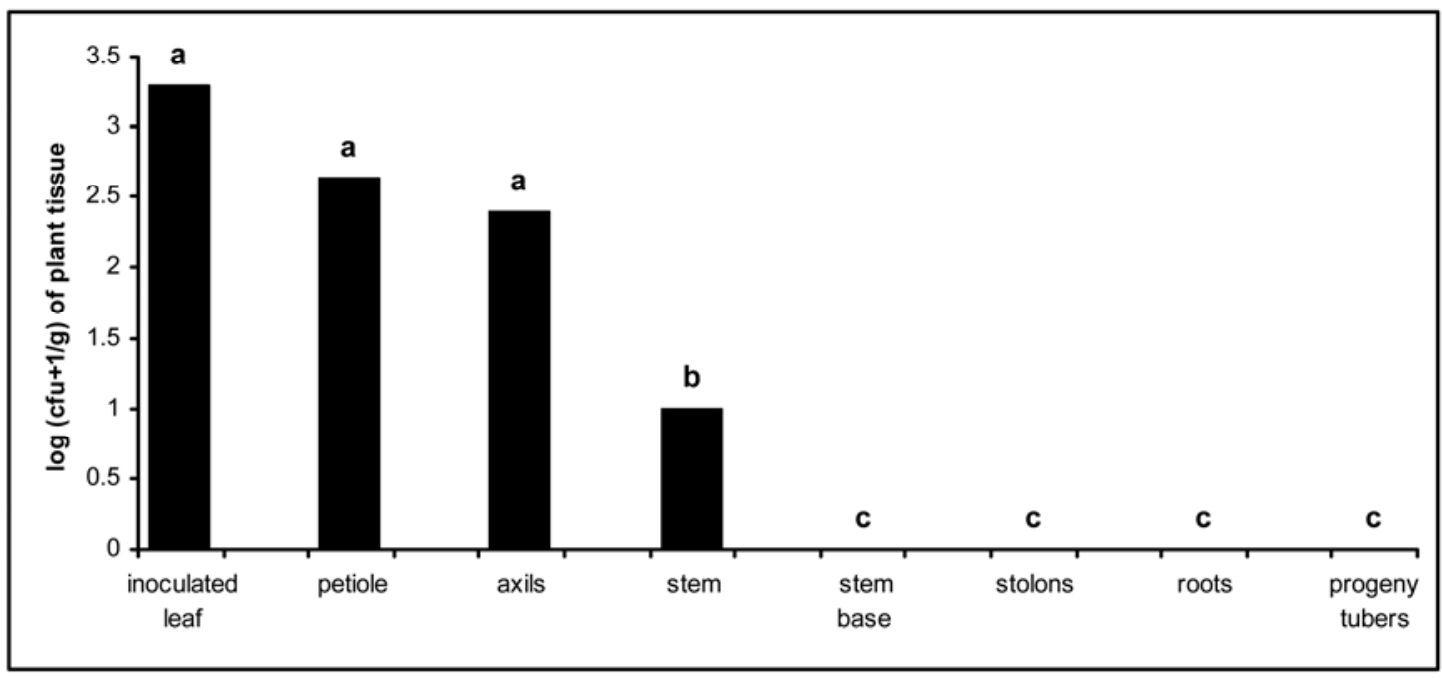

Fig. 3. Densities of Dickeya sp. IPO2254 (in $\log$ CFU $+1 \mathrm{~g}^{-1}$ of plant tissue) in A, stem-inoculated and B, leaf-inoculated plants 30 days postinoculation as determined by pour plating. Predicted values are averages from A, 20 and B, 16 individual plants from two independent experiments. Values followed by identical characters are not significantly different $(P=0.05)$. 
Dilution plating of leaf-inoculation plants. Leaf-inoculated plant samples were also examined $30 \mathrm{dpi}$ by pour-dilution plating (Fig. 3B). The densities of GFP-tagged Dickeya spp. found in inoculated leaves were generally low. The estimated density in the inoculated leaves was $1,000 \mathrm{CFU} \mathrm{g}^{-1}$; in leaf petioles and axils, $100 \mathrm{CFU} \mathrm{g}^{-1}$; and, in stems, only $10 \mathrm{CFU} \mathrm{g}^{-1}$ (Fig. 3B). On average, the GFP-tagged Dickeya sp. was found in $75 \%$ of the inoculated leaves, $88 \%$ of the leaf petioles, $63 \%$ in the axils, and $25 \%$ of stems directly attached to the axils of inoculated leaves (Table 1). We did not detect GFP-tagged Dickeya spp. in stem segments collected at ground level (stem base) or inside roots, stolons, and progeny tubers. In all, $70 \%$ of the leaf-inoculated plants exhibited disease symptoms at the inoculation point. Only low populations of GFP-tagged Dickeya spp. were observed in axils of leaves $\left(\approx 14 \mathrm{CFU} \mathrm{g}^{-1}\right)$ and main stems $\left(\approx 1.5 \mathrm{CFU} \mathrm{\textrm {g } ^ { - 1 }}\right)$
(Fig. 3B). However, in $25 \%$ of the tested plants, GFP-tagged bacteria were isolated from stem fragments taken near the inoculated compound leaves but not from the stem bases or underground part of the plants (roots, stolons, and progeny tubers). The densities of GFP-tagged Dickeya spp. in inoculated leaves, leaf petioles, and axils were not statistically different (Fig. 3B).

Microscopic observations of infected plant tissues. To determine in which plant tissue Dickeya sp. IPO2254 was present, different plant parts were analyzed with an epifluorescence stereomicroscope at low magnifications $(2.5 \times$ to 10$)$ and with a confocal laser-scanning microscope at a magnification of $640 \times$ to $1,000 \times$.

$E S M$. In stem-inoculated plants, a GFP signal was found in the vascular tissue of stems, stem bases, and stolons. In progeny tubers, the signal was observed in the vascular ring of the stolon end. In roots, the signal was detected in pith tissue (Fig. 4).
IPO2254
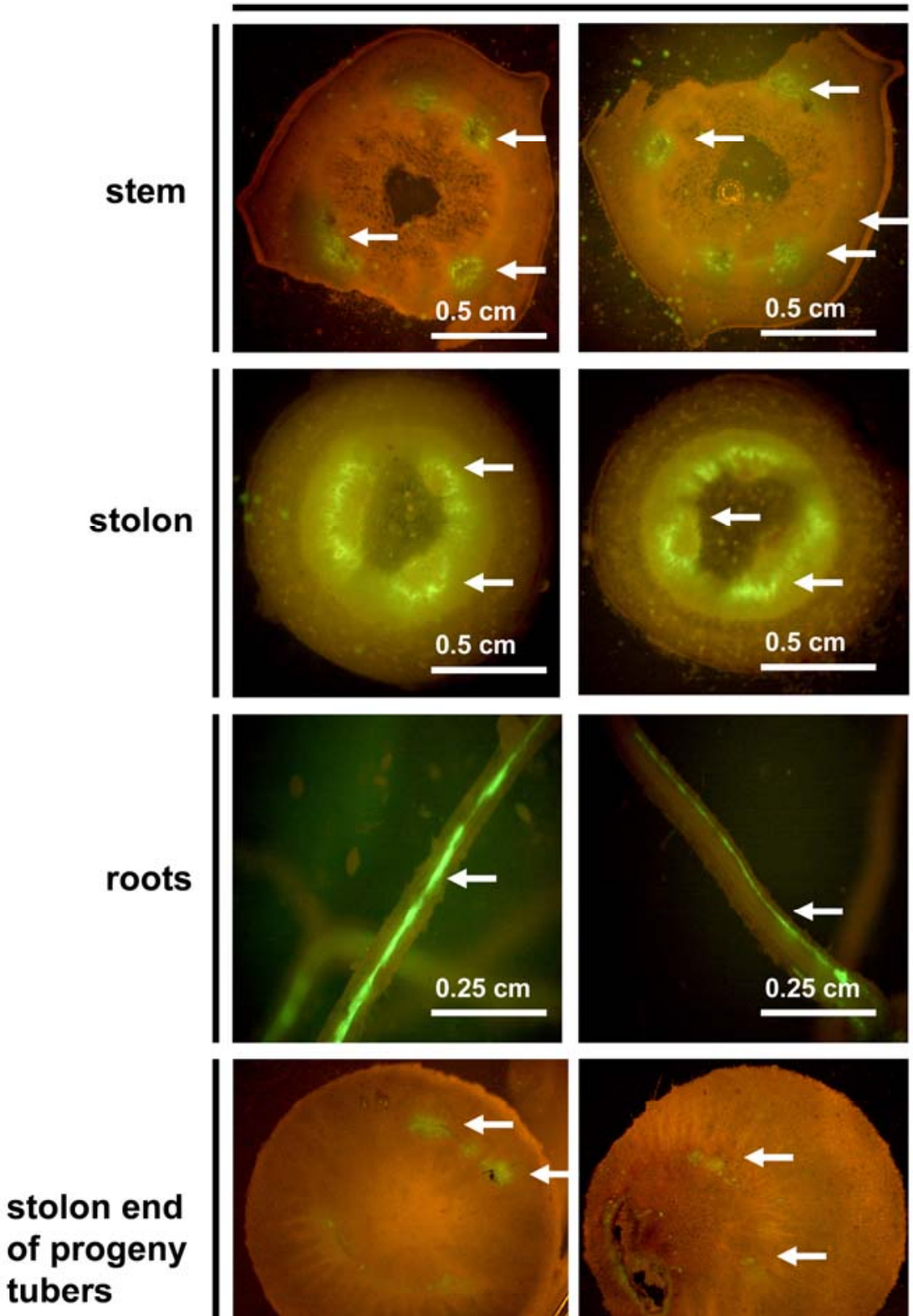
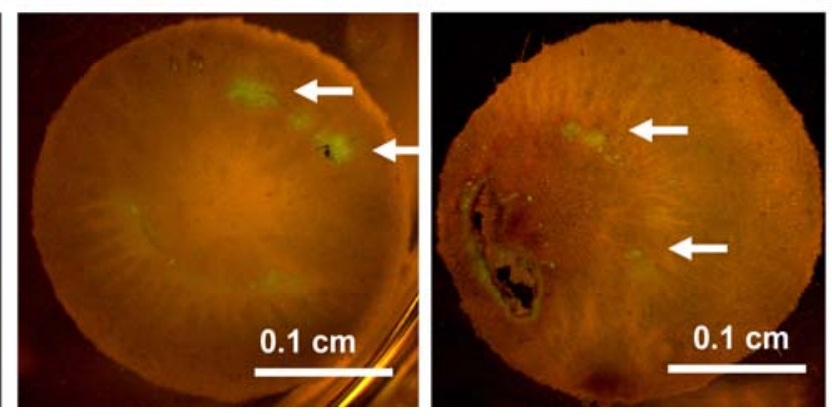

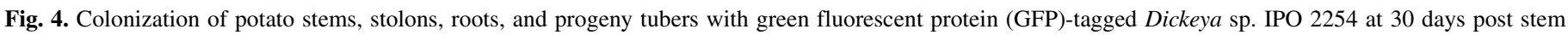

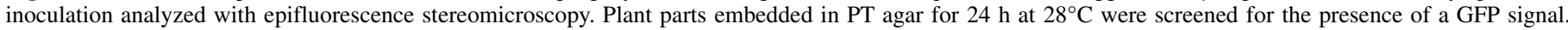

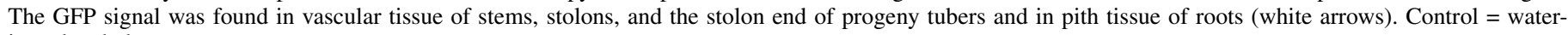
inoculated plants. 
In leaf-inoculated plants, a GFP signal was detected in the main vein of the leaves and inside petioles (Fig. 5) but not inside the stem basis (data not shown). We did not detect GFP-tagged Dickeya spp. in any water-inoculated control plant.

CLSM. Detailed studies with CLSM on the localization of GFP-tagged Dickeya spp. showed that, 30 days post stem inoculation, bacteria were mainly present inside xylem vessels and between protoxylem cells of stems, stem bases, and stolons. In roots of stem-inoculated plants, GFP-tagged bacteria were found inside parenchyma cells of pith tissue both inter- and intracellularly. In progeny tubers, GFP-tagged bacteria were found inside xylem and between xylem vessels of the stolon ends (Fig. 6). We did not do the CLSM studies on material from leafinoculated plants.

Characterization of GFP-expressing bacteria from infected plant tissue. Plant samples with a typical GFP signal observed under the epifluorescence microscope 30 dpi were collected, extracted, and plated on TSA or CVP. From stem-inoculated plants, 10 isolates were selected ( 2 from inoculation points, 2 from stems $10 \mathrm{~cm}$ below the inoculation point, 2 from roots, 2 from stolons, and 2 from progeny tubers). From leaf-inoculated plants, eight isolates were selected (two from the inoculated leaves, two from petioles, two from the axils, and two from stems). All isolates produced typical cavities on CVP, were green fluorescent in ESM, and were positive in a Dickeya sp.-specific PCR, showing the expected 420-bp PCR product (data not shown). Rep-PCR analyses showed that all fingerprints of isolates from stem- and leafinoculated plants were identical to strain Dickeya sp. IPO2254 and the parental wild-type strain Dickeya sp. IPO2222 used for GFP tagging (data not shown).

\section{DISCUSSION}

This study showed that inoculation of Dickeya sp. biovar 3 into the vascular system of stems can result in downward translocation and colonization of underground plant parts, including roots, stolons, and progeny tubers. Stem inoculation resulted in typical blackleg symptoms in the majority of infected plants. It was already known that Dickeya spp. could move upward in the vascular system inside plant tissue and cause systemic colonization of plants (32), as shown for stab-inoculated root cuttings of Chrysanthemum morifolium $(28,31)$ and naturally infected tomato plants (1). The downward movement of this bacterium, however, has not been described before.

The downward translocation of Dickeya spp. inside potato plants via xylem vessels is in agreement with our previous observations in which, after soil inoculation, a GFP-tagged Dickeya sp. was recovered from the xylem of symptomless stems (10). There are also reports of other plant-pathogenic bacteria that use xylem vessels to systemically colonize plant tissue. $X$. campestris pv. vitians is able to move inside xylem vessels in stab-inoculated lettuce plants (2) and Pseudomonas syringe pv. lachrymans is able to colonize cucumber seedlings via the xylem vessels (19).

In theory, there are three mechanisms by which bacteria are transported downward in xylem vessels: via degradation and embolism of xylem vessels followed by colonization of the xylem elements (26), via reverse water transport in xylem during dark periods (42), and upstream via pilus-driven twitching motility $(5,22)$. Degradation of xylem vessels leads to creation of large horizontal and vertical spaces filled with rotten tissue and bacterial slime that can be easily colonized. In general, degraded plant tissue near the infection point allows bacteria to move only short distances in infected tissue. The movement of $X$. campestris pv. vitians in lettuce stems, for example, was a result of mechanical damage of stems and embolism of the xylem (2), and the bacteria were only detected up to $2 \mathrm{~cm}$ below the inoculation point.

Water movement in xylem vessels drags the bacteria rapidly to distant plant parts. Movement of sap in xylem vessels is dependent upon evaporation of water from the surface of mesophyll cells (transpiration) in leaves, thereby pulling water up from the soil via the root system. Therefore, the directional movement of water is usually from roots to leaves (36). A reverse (downward)
IPO2254
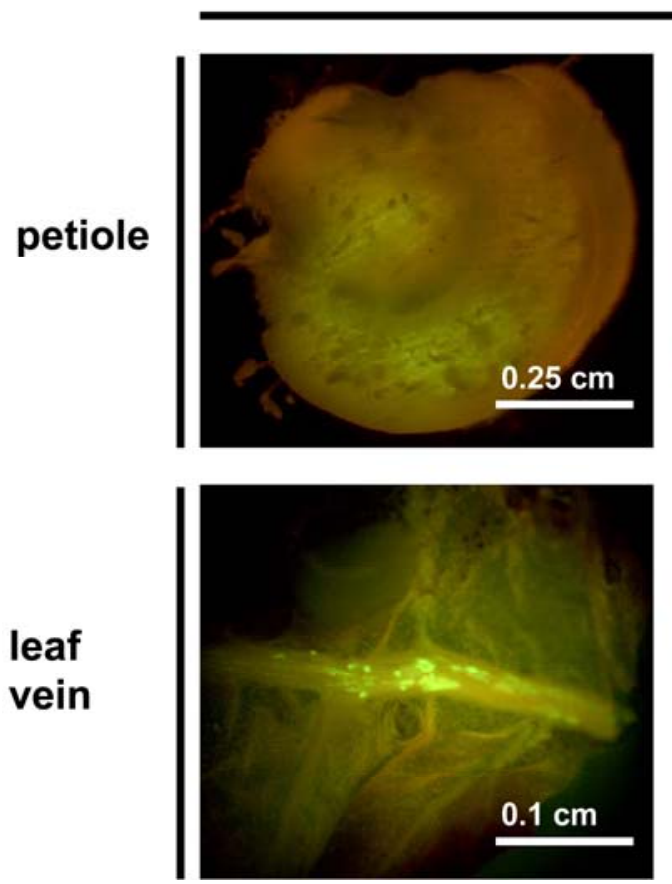
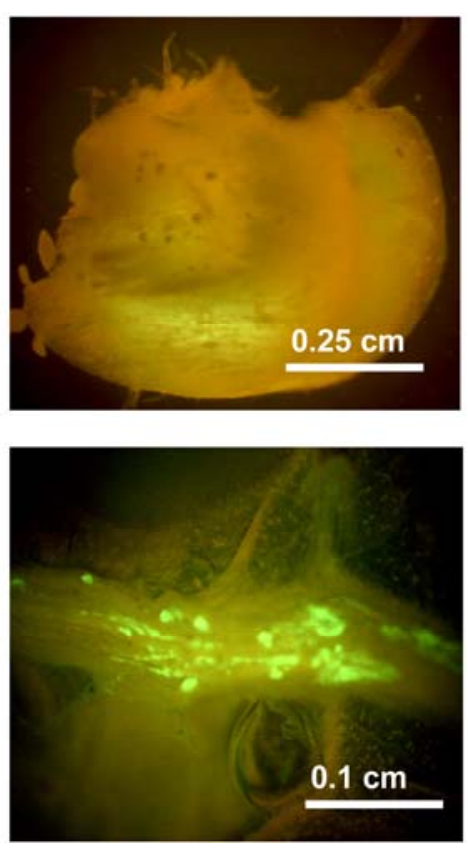

control
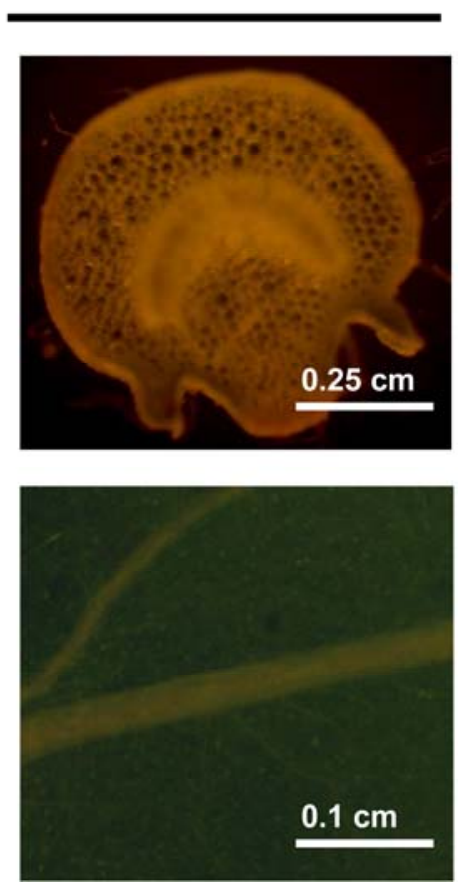

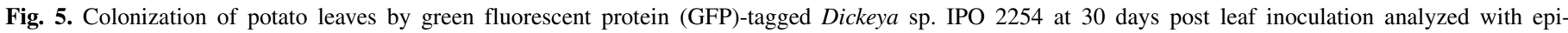

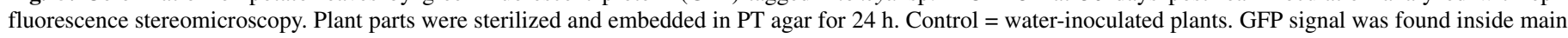
veins and inside petioles. 
water movement in xylem from leaves to roots only occurs when xylem sap is subjected to negative hydraulic pressure as a result of low water uptake from roots and reduced leaf evaporation. This is consistent with the cohesion-tension theory $(42,44)$. E. amylovora, for example, was recovered from the roots of apple seedlings after stem inoculation due to negative hydraulic pressure of the plant sap in xylem vessels (4).

Upstream migration in xylem vessels via twitching motility has been described for the nonmotile plant pathogen Xylella fastidiosa in grapevine (22). There is strong evidence that Ralstonia solanacearum can also move in xylem vessels of tomato plants via twitching motility (21). With $D$. dadanti, however, twitching motility could not be detected (12). Therefore we consider it unlikely that the Dickeya sp. biovar 3 strain can move via this form of migration.
Leaf-inoculated plants only harbored low Dickeya sp. populations in stems $30 \mathrm{dpi}$, indicating that the risk for translocation from infected leaves to progeny tubers is small. Downward vascular translocation from infected leaves may be limited to the low densities of Dickeya spp. present in leaf tissue but also by the stem-leaf junction physiology. Many vessels end in these junctions, and those nearby contain intervessel pit membranes (13). These membranes are part of the defense mechanism of the plant to protect vascular tissue from microorganisms that can infect leaves (9).

The risks of systemic infections after contamination of leaves will depend not only on the efficiency of translocation of bacteria but also in the ability of Dickeya spp. to survive the phyllosphere. The phyllosphere is recognized as a harsh environment in which, most of the time, bacteria are subjected to nutrient limitation,

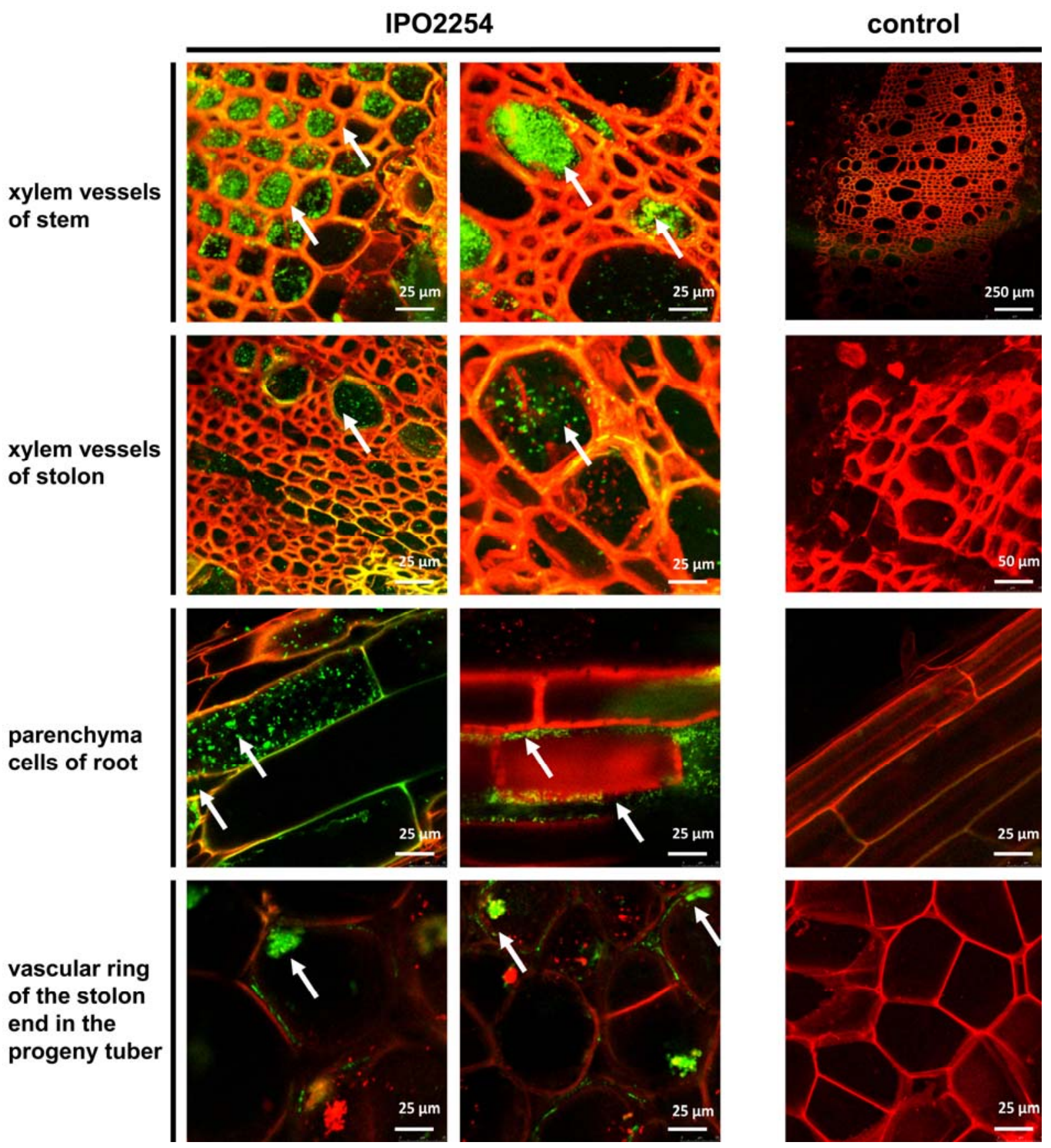

Fig. 6. Colonization of xylem vessels of potato stems, stolons, parenchyma cells of roots, and the stolon end containing xylem elements of progeny tubers by green fluorescent protein-tagged Dickeya sp. IPO2254 at 30 days post stem inoculation analyzed with confocal laser-scanning microscopy. Plant parts were embedded in PT agar for $24 \mathrm{~h}$ prior to analyses. Plant cells were counterstained with the red-fluorescent dye propidium iodide. Bacteria were found inside xylem vessels in stems and stolons, inside and between parenchyma cells in roots, and inside xylem cells of the vascular ring of the stolon end in progeny tubers (white arrows). 
desiccation, direct UV, and visible radiation stress $(3,6,15,41)$. It has been reported that Dickeya spp. are sensitive to drought and direct UV radiation (41); therefore, they are not expected to survive for long periods on the leaf surface.

Our results suggest that stem infection during cultivation practices can result in infected progeny due to the internal movement of Dickeya spp. to underground plant parts. Infection of stems resulting in aerial stem rot under wet conditions occurs via the use of contaminated machines, pest insects, or humans and animals $(8,33)$.

The risks of systemic colonization of potato plants from aerial stem infections will depend on various factors such as potato cultivar, Dickeya sp., initial inoculum, air temperature, and humidity. The conditions in our experiments were highly favorable for disease development. Tubers of cv. Kondor were used, which are highly susceptible to Dickeya spp. (H. Velvis, personal communication). High bacterial densities of a strain belonging to a new genetic clade of Dickeya sp. biovar 3, which appears to be highly virulent (unpublished results), were used. Also, the high temperature and high relative humidity in the greenhouse favored disease development. Field studies are required to further determine, in practice, the risks of infection of progeny tubers via haulm infections.

\section{ACKNOWLEDGMENTS}

The project was financed by the Dutch Ministry of Agriculture, Nature and Food Quality (research programme BO-06) and by the STW Foundation (Technologiestichting STW) (grant no. 10306, "Curing seed potato from blackleg-causing bacteria"). We thank I. Yedidia (Department of Ornamental Horticulture, ARO, Volcani Center, Israel) for providing the pPROBE-AT-gfp plasmid and M. C. M. Pérombelon (SCRI, UK) and L. J. Hyman (ex SCRI, UK) for their comments on the manuscript and their editorial work.

\section{LITERATURE CITED}

1. Alivizatos, A. S. 1985. Bacterial wilt of tomato in Greece caused by Erwinia chrysanthemi. Plant Pathol. 34:638-639.

2. Barak, J. D., Koike, S. T., and Gilbertson, R. L. 2002. Movement of Xanthomonas campestris pv. vitians in the stems of lettuce and seed contamination. Plant Pathol. 51:506-512.

3. Blakeman, J. P. 1991. Foliar bacterial pathogens: epiphytic growth and interactions on leaves. J. Appl. Bacteriol. Symp. Suppl. 70:49-59.

4. Bogs, J., Bruchmuller, I., Erbar, C., and Geider, K. 1998. Colonization of host plants by the fire blight pathogen Erwinia amylovora marked with genes for bioluminescence and fluorescence. Phytopathology 88:416-421.

5. Bove, J. M., and Garnier, M. 2002. Phloem and xylem-restricted plant pathogenic bacteria. Plant Sci. 163:1083-1098.

6. Burrage, S. W. 1976. Aerial micro-climate around plant surface. Pages 173-184 in: Microbiology of Aerial Plant Surface. C. H. Dickson and T. F. Preece, eds. Academic Press, London.

7. Cameron, A. C., and Trivedi, P. K. 1998. Regression Analyses of Count Data. Econometric Society Monograph 30. Cambridge University Press, New York.

8. Charkowski, A. 2006. The soft rot Erwinia. Pages 423-505 in: PlantAssociated Bacteria. S. S. Gnanamanickam, ed. Springer, The Netherlands.

9. Chatelet, D. S., Matthews, M. A., and Rost, T. L. 2006. Xylem structure and connectivity in grapevine (Vitis vinifera) shoots provides a passive mechanism for the spread of bacteria in grape plants. Ann. Bot. 98:483494.

10. Czajkowski, R., de Boer, W., Velvis, J. H., and van der Wolf, J. M. 2010. Systemic colonization of potato plants by soil-borne, GFP-tagged strain of Dickeya sp. biovar 3. Phytopathology 100:134-142.

11. Czajkowski, R., Grabe, G., and van der Wolf, J. M. 2009. Distribution of Dickeya spp. and Pectobacterium carotovorum subsp. carotovorum in tubers of naturally infected seed potatoes. Eur. J. Plant Pathol. 125:263275.

12. El Hassounti, M., Chambost, J. P., Expert, D., Van Gijsegem, F., and Barras, F. 1999. The minimal gene set member $m s r A$, encoding peptide methionine sulfoxide reductase, is a virulance determinant of the plant pathogen Erwinia chrysanthemi. Proc. Natl. Acad. Sci. USA 96:887-892.

13. Fisher, D. G., and Larson, P. R. 1983. Structure of leaf/branch gap parenchyma and associated vascular tissues in Populus deltoides. Bot.
Gaz. 144:73-85.

14. Fisher, P. J., Broad, S. A., Clegg, C. D., and Lappin Scott H. M. 1993. Retention and spread of a genetically engineered pseudomonad in seeds and plants of Zea mays; a preliminary study. New Phytol. 124:101-106.

15. Gouesbet, G., Jebber, M., Bonnassie, S., Hugouvieux-Cotte-Pattat, N., Himdi-Kabbab, S., and Blanco, C. 1995. Erwinia chrysanthemi at high osmolarity: influence of osmoprotectants on growth and pectate lyase production. Microbiology 141:1407-1412.

16. Hilbe, J. M. 2007. Negative Binominal Regression. Cambridge University Press, United Kingdom.

17. Hyman, L. J., Sullivan, L., Toth, I. K., and Perombelon. M. C. M. 2001. Modified crystal violet pectate medium (CVP) based on a new polypectate source (Slendid) for the detection and isolation of soft rot erwinias. Potato Res. 44:265-270.

18. Janse, J. D., and Ruissen, M. A. 1988. Characterization and classification of Erwinia chrysanthemi strains from several hosts in The Netherlands. Phytopathology 78:800-808.

19. Kritzman, G., and Zutra Z. 1983. Systemic movement of Pseudomonas syringe pv. lachrymans in the stem, leaves, fruits and seeds of cucumber. Can. J. Plant Pathol. 5:273-278.

20. Laurila, J., Ahola, V., Lehtinen, A., Joutsjoki, T., Hannukkala, A., Rahkonen, A., and Pirhonen, M. 2008. Characterization of Dickeya strains isolated from potato and river water samples in Finland. Eur. J. Plant Pathol. 122:213-225.

21. Liu, H. L., Kang, Y. W., Genin, S., Schell, M. A., and Denny, T. P. 2001. Twitching motility of Ralstonia solanacearum requires a type IV pilus system. Microbiology 147:3215-3229.

22. Meng, Y., Li, Y., Galvani, C. D., Hao, G., Turner, J. N., Burr, T. J., and Hoch, H. C. 2005. Upstream migration of Xylella fastidiosa via pilusdriven twitching motility. J. Bacteriol. 187:5560-5567.

23. McCullagh, P., Nelder, J. A. 1989. Generalized Linear Models, second ed. Chapman and Hall/CRC, Boca Raton, FL and London.

24. Miller, W. G., Leveau, J. H. J., and Lindow, S. E. 2000. Improved gfp and inaZ broad-host-range promoter-probe vectors. Mol. Plant-Microbe Interact. 13:1243-1250.

25. Nassar, A., Darrasse, A., Lemattre, M., Kotoujansky, A., Dervin, C., Vedel, R., and Bertheau, Y. 1996. Characterization of Erwinia chrysanthemi by pectinolytic isozyme polymorphism and restriction fragment length polymorphism analysis of PCR-amplified fragments of pel genes. Appl. Environ. Microbiol. 62:2228-2235.

26. Nelson, P. E., and Dickey, R. S. 1970. Histopathology of plants infected with vascular bacterial pathogens. Annu. Rev. Phytopathol. 8:259-280.

27. Payne, R. W., Murray, D. A., Harding, S. A., Baird, D. B., and Souter, D. M. 2009. GenStat for Windows (12th ed.) Introduction. VSN International, Hemel Hempstead.

28. Pennypacker, B. W., Smith, C. M., Dickey, R. S., and Nelson, P. E. 1981. Histopathology of a symptomless chrysanthemum cultivar infected by Erwinia chrysanthemi or E. carotovora subsp. carotovora. Phytopathology 71:141-148.

29. Perombelon, M. C. M. 1992. Potato blackleg: epidemiology, hostpathogen interaction and control. Neth. J. Plant Pathol. 98:135-146.

30. Perombelon, M. C. M. 2000. Blackleg risk potential of seed potatoes determined by quantification of tuber contamination by the causal agent and Erwinia carotovora subsp. atroseptica: a critical review. EPPO Bull. 30:413-420

31. Perombelon, M. C. M. 2002. Potato diseases caused by soft rot erwinias: an overview of pathogenesis. Plant Pathol. 51:1-12.

32. Perombelon, M. C. M., and Hyman, L. J. 1988. Effect of latent infection by Erwinia on yield. In: Scottish Crop Research Institute Annual Report, Dundee, UK.

33. Perombelon, M. C. M., and Kelman, A. 1980. Ecology of the soft rot Erwinias. Annu. Rev. Phytopathol. 18:361-387.

34. Perombelon, M. C. M., and van der Wolf, J. M. 2002. Methods for the Detection and Quantification of Erwinia carotovora subsp. atroseptica (Pectobacterium carotovorum subsp. atrosepticum) on Potatoes: A Laboratory Manual. Scottish Crop Research Institute Ocasional Publication No. 10.

35. Prins, H., and Breukers, A. 2008. In de puree? De gevolgen van aantasting door Erwinia voor de pootaardappelsector in kaart gebracht. LEI, Den Haag, The Netherlands.

36. Rand, R. H. 1983. Fluid mechanics of green plants. Annu. Rev. Fluid Mech. 15:29-45.

37. Samson, R., Legendre, J. B., Christen, R., Fischer-Le Saux, M., Achouak, W., and Gardan, L. 2005. Transfer of Pectobacterium chrysanthemi (Burkholder et al. 1953) Brenner et al. 1973 and Brenneria paradisiaca to the genus Dickeya gen. nov. as Dickeya chrysanthemi comb. nov. and Dickeya paradisiaca comb. nov. and delineation of four novel species, Dickeya dadantii sp. nov., Dickeya dianthicola sp. nov., Dickeya dieffenbachiae sp. nov. and Dickeya zeae sp. nov. Int. J. Syst. Evol. Microbiol. 55:1415-1427. 
38. Schmee, J., and Hahn, G. J. 1979. A simple method for regression analysis with censored data. Technometrics 21:417-432.

39. Scott, R., Chard, J., Hocart, M., Lennard, J., and Graham, D. 1996. Penetration of potato tuber lenticels by bacteria in relation to biological control of blackleg disease. Potato Res. 39:333-344.

40. Slawiak, M.,. Beckhoven, J. R. C. M, Speksnijder, A. G. C. L., Czajkowski, R., Grabe, G., and van der Wolf, J. M. 2009. Biochemical and genetical analysis reveal a new clade of biovar 3 Dickeya spp. strains isolated from potato in Europe. Eur. J. Plant Pathol. 125:245-261.

41. Sundin, G. W. 2002. Ultraviolet radiation on leaves: its influence on microbial communities and their adaptations. Pages 27-41 in: Phyllosphere Microbiology. S. E. Lindow, E. I. Hecht Pointer, and V. J. Elliot, eds. American Phytopathological Society Press, St. Paul, MN.
42. Tatter, T. A., and Tatter, S. J. 1999. Evidence for the downward movement of materials injected into trees. J. Arboricult. 25:325-332.

43. Tsror, L., Erlich, O., Lebiush, S., Hazanovsky, M., Zig, U., Slawiak, M., Grabe, G., van der Wolf, J. M., and van de Haar, J. J. 2008. Assesment of recent outbreaks of Dickeya sp. (syn. Erwinia chrysanthemi) slow wilt in potato crops in Israel. Eur. J Plant Pathol. 123:311-320.

44. Tyree, M. T. 1997. The cohesion-tension theory of sap ascent: current controversies. J. Exp. Bot. 48:1753-1765.

45. Velvis, H., and van der Wolf, J. M. 2009. Bacterievrije pootgoedteelt, een uitdaging! - eindrapportage 2005-2008. HZPC, PRI, The Netherlands.

46. Versalovic, J., Schneider, M., De Bruijn, F. J., and Lupski, J. R. 1994. Genomic fingerprinting of bacteria using repetitive sequence-based polymerase chain reaction. Method Mol. Cell. Biol. 5:25-40. 